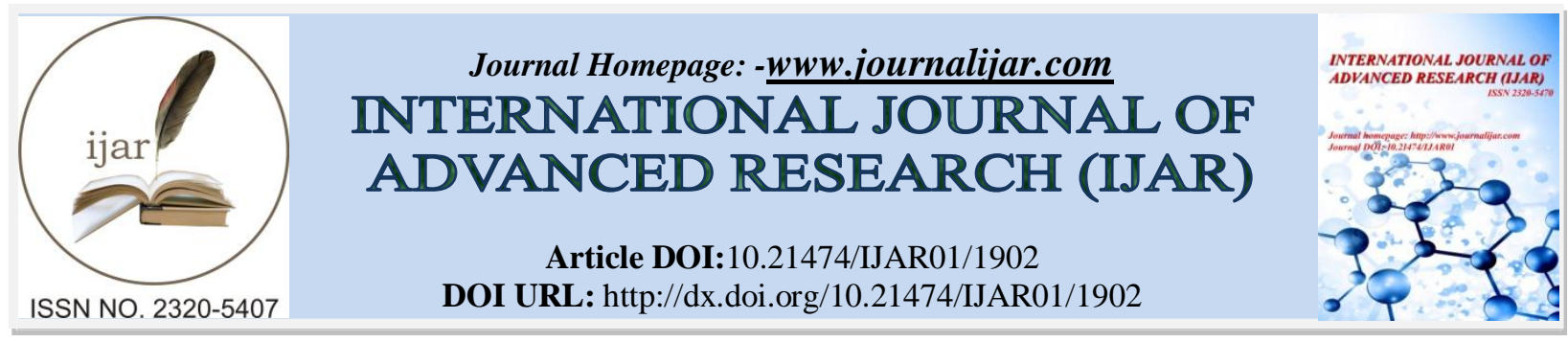

RESEARCH ARTICLE

\title{
LEVEL OF COMPLIANCE AMONG DIABETIC AND HYPERTENSIVE PATIENTS AND AFFECTING FACTORS IN AL-MADINA, KINGDOM OF SAUDI ARABIA.
}

Hamza Bali, Yousef Ekhmimi, Mohammed Khan, Mahmoud Alkhayat and Amal Arruhaily. Faculty of Medicine, Taibah University, Al-Madina Al-Munawwarah, Kingdom of Saudi Arabia.

\section{Manuscript Info}

Manuscript History

Received: 12 August 2016

Final Accepted: 12 September 2016

Published: October 2016

Key words:-

Compliance, Diabetes Mellitus,

Hypertension, follow up.

\section{Abstract}

Introduction:-Chronic disease, such as diabetes mellitus and hypertension, is a condition that requires compliance to health care provider's recommendations to be under control. When a chronic disease is inadequately managed, the condition may worsen.

Objectives:- To determine the level of compliance among diabetic and hypertensive patients and the factors affecting their compliance.

Methods:-A cross sectional analytic study was conducted and included diabetic and hypertensive patients participated in the campaign (Your Health is Your Life VI) held in Al-Medina. Data collected by administering a questionnaire and measuring glycosylated hemoglobin and blood pressure for all participants.

Results:-Among 104 participants included in this study the level of compliance was $47.1 \%$ to regular follow-up, $53.8 \%$ to medications, $66.3 \%$ to doctor's advice on diet and $62.5 \%$ on exercise. Urban participants have a higher percentage in compliance to regular follow up and medications comparing to rural. The age above 41 years associated with better compliance to advices on diet. Participants with both diabetes and hypertension and those managed by pills have better compliance to other medications. An excellent patient-doctor relationship, feeling satisfied after each visit and good information about health state associate with good compliance to regular follow up and doctor's advices on diet and exercise. The forgetfulness was the cause of non-compliance in more than half of participants.

Conclusion:-The compliance was good among almost half of the participants and it was significantly associated with good patientdoctor relationship. The most affecting factors was related to the presence of co-morbidities and type of prescribed medications.

Copy Right, IJAR, 2016,. All rights reserved.

\section{Introduction:-}

Diabetes mellitus and hypertension are chronic diseases that required compliance to management and regular follow up to control the disease and prevent complications. World health organization defined compliance as "the extent to which a person's taking medication behavior, following a diet and/or executing life style changes, corresponds with agreed recommendations from health care providers"(1). 
Hypertension and diabetes mellitus are common diseases worldwide (2). Hypertension is defined as persistent elevation of systolic blood pressure (SBP) $\geq 140 \mathrm{~mm} \mathrm{Hg}$ and/or diastolic blood pressure (DBP) $\geq 90 \mathrm{~mm} \mathrm{Hg}$ based on at least two readings on separate occasions in adults who are not on antihypertensive medications(3). Chronically, this elevation is associated with a higher risk of renal, cardiac, and brain damage, as well as with other diseases (4). Worldwide, it is estimated to cause 7.5 million deaths, about $12.8 \%$ of the total of all deaths (5). A study on about 17,230 of Saudi population showed that the prevalence of hypertension in Kingdome of Saudi Arabia is about $26.1 \%$ (6). The prevalence of hypertension is projected in year 2025 to increase by $24 \%$ in developed countries and $80 \%$ in developing countries (7).

Diabetes mellitus (DM) is a chronic progressive metabolic disorder characterized by hyperglycemia mainly due to absolute (Type 1 DM) or relative (Type 2 DM) deficiency of insulin hormone. DM virtually affects every system of the body mainly due to metabolic disturbances caused by hyperglycemia, especially if diabetes control over a period of time proves to be suboptimal (8).

Diabetes is associated with complications such as cardiovascular diseases, nephropathy, retinopathy and neuropathy, which can lead to chronic morbidities and mortality $(9,10)$. Saudi Arabia has the second highest rate of diabetes in the Middle East and is seventh highest in the world, according to the World Health Organization. Prevalence of diabetes in Saudi Arabia among adults (20-79 years) at 2014 is $20.5 \%$ (11).

When a chronic illness is inadequately managed, the condition may worsen (12).Non-compliant patients are those whose health-seeking or maintenance behaviors lack congruence with the recommendations prescribed by a healthcare provider (13).Patient non-compliance is a serious healthcare concern that poses a great challenge to the successful delivery of healthcare. This is widespread and has been reported from all over the world (14).

Factors most often cited as contributing significantly to compliance are the nature of the patient-provider interaction, specific psychological and social characteristics of the patient, and the amount and type of support given the patient in his or her environment (15). Other many factors can affect general compliance as: misunderstanding of prescribed instructions, frequent changes to drug regimens, multiple health care providers prescribing medications, limited faith in the medications, forgetfulness, physical difficulties limiting access to or use of medication, limited education about the illness or the need for medication, few symptoms, chronic illness, a complicated regimen, polypharmacy (use of multiple medications for the treatment of a patient's medical conditions),cost of drugs, and real or perceived adverse drug reactions (16).

This topic in spite of its importance, is not well understood in our country.

\section{Objectives:-}

1. To determine the level of compliance among diabetic and hypertensive patients.

2. To determine the factors affecting their compliance.

\section{Methodology:-}

Study design and participants:-

Cross-sectionalanalyticalstudy was conducted and included 104 participants previously diagnosed with diabetes mellitus and/or hypertension during the event of "Your Health is Your Life Fourth Campaign" in the period from 8/6/2015 till 14/6/2015 for seven days, which was organized by Taibah Medical Club, Madinah, Saudi Arabia. It was conducted at the main place of the campaign "Al-Rashid Mega Mall, Madina" as well as through scheduled visits to some governmental agencies such as Al Madinah branch of Ministry of Education, Al Madinah branch of Ministerial agency of civil affairs, $\mathrm{Al}$ Madinah branch of directorate general of passports and $\mathrm{Al}$ Madinah branch of ministry of labor.

The study was designed to assess the level of compliance among patients with hypertension and/or diabetes mellitus and affecting factors. The participants were selected based on inclusion and exclusion criteria which include people who were previously diagnosed with hypertension and/or diabetes mellitus in a health clinic by a physician at least 6 months ago and on prescribed medications. Age of participants should be 18 years or more. The study excluded participants who have recently diagnosed with hypertension and/or diabetes mellitus for less than 6 months, gestational diabetes or less than 18 years old. 


\section{Data collection:-}

A self-administered questionnaire form "papers" has been developed to assess the level of compliance and affecting factors. The questionnaire was translated into Arabic and was pretested. It included sections on socio-demographic data (age, gender, occupation, marital status, level of education, income level and residency) and data about patients' chronic diseases and the prescribed medications. Also, it was containing questions to assess their level of compliance regarding to regular follow up, adherence to treatments and following doctor's advices on diet and exercise as well as patient-doctor relationship.

The patient was considered to be compliant to regular follow up if had not missed more than one appointment in the last one year. Medications non-compliance was defined as missing two or more doses of medications over a period of 7 days prior to the date of study. Compliance to doctor's advices on diet and exercise determined by asking the patient if he following the doctor's advice on it.

The questionnaire is sub-structured with the measurements of blood pressure and glycosylated hemoglobin (HA1C) for

Blood pressure and glycosylated hemoglobin was measured to determine the level of control. Control of hypertension was defined as systolic blood pressure <140 $\mathrm{mmHg}$ and diastolic blood pressure <90 $\mathrm{mmHg}$. Participating diabetic patients were divided into two groups: patients with $\mathrm{HbA} 1 \mathrm{c}$ of $7 \%$ or more and those with less than 7\%. This classification was based on the American Diabetes Association (ADA) guidelines. Blood pressure was measured using both mercury sphygmomanometer and Welch Allyn electronic sphygmomanometer with appropriate cuff sizes and at least 2 measurements after 5 minutes rest. Glycosylated hemoglobin was measured by using kits of A1cNow from Bayer.

\section{Data analysis:-}

Data were analysed by using Statistical Package for Social Science Software (SPSS) version 18. Association between the level of compliance (to regular follow up, medications and doctor's advice on diet and exercise) and independent variables related to patients, diseases, medications characteristics and patient-doctor relationship were determined by using Chi-square and Fisher's exact tests. Statistical significance was set at $\mathrm{P}$ value $<0.05$.

\section{Ethical consideration:-}

The study had an approval from research and human ethics committee in Taibah University. The participants were informed about the objectives of the study and confidentiality of the data. Verbal consent was obtained from all the subjects and they participated voluntarily in the study.

\section{Results:-}

A total number of 104 participants included in this study, thirty four of them had both diabetes mellitus and hypertension (32.69\%), fifty of them had diabetes mellitus only(48.08\%), and twenty of them had hypertension only $(19.23 \%)$.

Regarding regularity of follow up $41.3 \%$ of participants $(n=43)$ had not missed any appointment in the last one year, while 5.8\% $(\mathrm{n}=6)$ had missed an appointment once, 31.7\% $(\mathrm{n}=33)$ twice, and $21.2 \%(\mathrm{n}=22)$ more than twice. The reason for missed appointment was no time among 26\%, 9.6\% forgetfulness, $9.6 \%$ no need for attend (neglecting), $7.7 \%$ difficulty in transport and financial problems and $4.8 \%$ due to travel.

According to medication compliance 32.69\% ( $\mathrm{n}=34$ ) had not missed their medications in the last one week, $21.15 \%$ $(n=22)$ had missed their medications once and $46.15 \%(n=48)$ twice and more.

The forgetfulness was the cause of non-compliance in more than half of participants. Theparticipants also reported other causes such as multiple-medications (14.3\%), change time of sleeping (14.3), limited faith in the medications $(8.2 \%)$ and lack of symptoms $(6.1 \%)$.

$66.3 \%$ of participantes $(n=69)$ said that they are following doctor's advice on diet and $62.5 \%(n=65)$ on exercise.

There were statistically significant differences $(\mathrm{p}<0.05)$ in compliance to regular follow up and medications between participants regarding to residency. The urban participants had a higher percentage in compliance to regular follow 
up $(51.60 \%)$ comparing to rural participants $(15.40 \%)$. The compliance to medications among urban participants was $(58.20 \%)$ while $(23.10 \%)$ among rural participants.

Table 1:-Socio-demographic Data of the participants.

\begin{tabular}{|c|c|}
\hline & Percentage (no) \\
\hline $\begin{aligned} \text { Age: } & \\
\bullet & 18-30 \\
\bullet & 31-40 \\
\bullet & 41-50 \\
\bullet & \text { More than } 50\end{aligned}$ & $\begin{array}{l}15.40 \%(16) \\
21.20 \%(22) \\
31.70 \%(33) \\
31.70 \%(33)\end{array}$ \\
\hline $\begin{aligned} \text { Gender: } & \\
\bullet & \text { Male } \\
\bullet & \text { Female }\end{aligned}$ & $\begin{array}{l}53.80 \%(56) \\
46.20 \%(48)\end{array}$ \\
\hline $\begin{array}{cl}\text { Occupation: } \\
\text { - } & \text { Student } \\
\text { - } & \text { Unemployed } \\
\text { - } & \text { Administrative } \\
\text { - } & \text { Teacher } \\
\text { - } & \text { Military } \\
\text { - } & \text { Engineer } \\
\text { - } & \text { Doctor } \\
\end{array}$ & $\begin{array}{l}7.70 \%(8) \\
44.20 \%(46) \\
23.10 \%(24) \\
11.50 \%(12) \\
10.60 \%(11) \\
1.90 \%(2) \\
1.00 \%(1)\end{array}$ \\
\hline $\begin{array}{cl}\text { Educational Level: } \\
\text { - } \\
\text { - } & \text { Illiterate } \\
\text { - } & \text { Intermary } \\
\text { - } & \text { High School } \\
\text { - } & \text { Higher Education } \\
\end{array}$ & $\begin{array}{l}10.60 \%(11) \\
10.60 \%(11) \\
15.40 \%(16) \\
31.70 \%(33) \\
31.70 \%(33)\end{array}$ \\
\hline $\begin{array}{c}\text { Residence: } \\
\text { • Urban } \\
\bullet \quad \text { Rural }\end{array}$ & $\begin{array}{l}98.08 \%(102) \\
1.92 \%(2)\end{array}$ \\
\hline
\end{tabular}

There was statistically significant difference $(\mathrm{p}<0.05)$ in compliance to doctor's advices on diet regarding to age. Patients between 41 and 50 years old hada highest percentage in compliance to doctor's advice on diet (78.80\%)followed by those above 50 years old $(75.80 \%)$ then those between 18 and 30 years $(50.00 \%)$ and lastly participants between 31 and $40(45.50 \%)$. Other socio-demographic factors discussed in our study showed no statistically significant differences.

The compliance to medications was better among those had both diabetes mellitus and hypertension (64.70\%) followed by those had diabetes mellitus only (58.00\%) and lastly those had hypertension only (25.00\%). Among the hypertensive participants with good compliance to regular follow up and medications $77.3 \%$ and $81.5 \%$, respectively, had controlled blood pressure $(<140 / 90 \mathrm{mmHg})$. Among the diabetic participants with good compliance to regular follow up and medications (40.5\%) and $(37.3 \%)$,respectively, achieved the target level of glycemic control (HA1C <7\%).

Table2,3,4\&5 show that there were statistically significant differences between participants in compliance to regular follow up and doctor's advice on diet and exercise regarding patient doctor relationship. Participants who said that the doctor versed about their health state and give them enough information about it had a higher percentage in compliance to regular follow up (54.90\%) (52.30\%) respectively as well as in compliance to doctor's advices on diet (74.4\%) (81\%) and exercise (67.10\%) (68.60\%) respectively. Participants with excellent relationship with their doctor and feel satisfied after each visit had better compliance to regular follow up (62.50\%) $(60.30 \%)$ respectively, and to doctor's advices on diet (79.7\%) (81\%) and exercise(71.9\%) (79.4\%) respectively. When doctor answer about all patients' questions regarding their health state and disease they complying more to his advices on diet (72.7\%) and exercise (67\%). The compliance to medications shows no significant association with patient doctor relationship. 
Table 6. shows that there was statically significant association between type of diabetic medications and patient's compliance to medications. Patients on pills only had higher percentage in compliance (84.8\%) in comparing to those with insulin $(48.7 \%)$ or both insulin and pills (33.3\%). Other characters of prescribed medications show no significant association with compliance.

Table 2:- Association between level of compliance to regular follow up and patient doctor relationship.

\begin{tabular}{|c|c|c|c|}
\hline & Compliance & Non-compliance & $\mathrm{P}$ value \\
\hline $\begin{array}{l}\text { Do you think your doctor is } \\
\text { versed about your health state? } \\
\text { - Yes } \\
\text { - No }\end{array}$ & $\begin{array}{l}54.90 \%(45) \\
18.20 \%(4)\end{array}$ & $\begin{array}{l}45.10 \%(37) \\
81.80 \%(18)\end{array}$ & $* 0.002$ \\
\hline $\begin{array}{l}\text { How is your relationship with your doctor? } \\
\text { - Excellent } \\
\text { - Medium } \\
\text { - Bad }\end{array}$ & $\begin{array}{l}62.50 \%(40) \\
21.90 \%(7) \\
25.00 \%(2) \\
\end{array}$ & $\begin{array}{l}37.50 \%(24) \\
78.10 \%(25) \\
75.00 \%(6)\end{array}$ & $*<0.001$ \\
\hline $\begin{array}{l}\text { Do you feel satisfied after each } \\
\text { visit? } \\
\text { - Always } \\
\text { - Sometimes } \\
\text { - Never }\end{array}$ & $\begin{array}{l}60.30 \%(38) \\
28.60 \%(8) \\
23.10 \%(3)\end{array}$ & $\begin{array}{l}39.70 \%(25) \\
71.40 \%(20) \\
76.90 \%(10)\end{array}$ & $* 0.004$ \\
\hline $\begin{array}{l}\text { Does your doctor give you enough information } \\
\text { about your health } \\
\text { state? } \\
\text { - Yes } \\
\text { - No }\end{array}$ & $\begin{array}{l}52.30 \%(45) \\
22.20 \%(4)\end{array}$ & $\begin{array}{l}47.70 \%(41) \\
77.80 \%(14)\end{array}$ & $* 0.02$ \\
\hline $\begin{array}{l}\text { Does your doctor answer you about all your } \\
\text { question about your health and diseases? } \\
\text { - Yes } \\
\text { - No }\end{array}$ & $\begin{array}{l}51.10 \%(45) \\
25.00 \%(4)\end{array}$ & $\begin{array}{l}84.90 \%(43) \\
75.00 \%(12)\end{array}$ & 0.054 \\
\hline
\end{tabular}

Table 3:- Association between level of compliance to medications and patient doctor relationship.

\begin{tabular}{|c|c|c|c|}
\hline & Compliance & Non-compliance & P value \\
\hline $\begin{array}{l}\text { Do you think your doctor is } \\
\text { versed about your health state? } \\
\text { - Yes } \\
\text { - No } \\
\end{array}$ & $\begin{array}{l}54.90 \%(45) \\
50.00 \%(11)\end{array}$ & $\begin{array}{l}45.10 \%(37) \\
50.00 \%(11)\end{array}$ & 0.684 \\
\hline $\begin{array}{l}\text { How is your relationship with your doctor? } \\
\text { - Excellent } \\
\text { - Medium } \\
\text { - Bad }\end{array}$ & $\begin{array}{l}57.80(37) \\
46.90 \%(15) \\
50.00 \%(4)\end{array}$ & $\begin{array}{l}42.20 \%(27) \\
53.10 \%(17) \\
50.00 \%(4)\end{array}$ & .583 \\
\hline $\begin{array}{l}\text { Do you feel satisfied after each visit? } \\
\text { - Always } \\
\text { - Sometimes } \\
\text { - Never }\end{array}$ & $\begin{array}{l}58.7 \%(37) \\
42.90 \%(12) \\
53.80 \%(7)\end{array}$ & $\begin{array}{l}41.30 \%(26) \\
57.10 \%(16) \\
46.20 \%(6)\end{array}$ & .374 \\
\hline $\begin{array}{l}\text { Does your doctor educate you very well about } \\
\text { your diseases } \\
\text { - Yes } \\
-\quad \text { No }\end{array}$ & $\begin{array}{l}54.70 \%(47) \\
50.00 \%(9)\end{array}$ & $\begin{array}{l}45.30 \%(39) \\
50.00 \%(9)\end{array}$ & .719 \\
\hline $\begin{array}{l}\text { Does your doctor answer you about all your } \\
\text { question about your health and diseases? } \\
\text { - Yes } \\
\text { - No }\end{array}$ & $\begin{array}{l}53.40 \%(47) \\
56.20 \%(9)\end{array}$ & $\begin{array}{l}46.60 \%(41) \\
43.80(7)\end{array}$ & 0.834 \\
\hline
\end{tabular}


Table 4:- Association between level of compliance to doctor's advices on diet andpatient doctor relationship.

\begin{tabular}{|c|c|c|c|}
\hline & Compliance & Non-compliance & $\mathrm{P}$ value \\
\hline $\begin{array}{l}\text { Do you think your doctor is } \\
\text { versed about your health state? } \\
\text { - Yes } \\
\text { - No }\end{array}$ & $\begin{array}{l}74.40 \%(61) \\
36.40 \%(8)\end{array}$ & $\begin{array}{l}25.60 \%(21) \\
63.60 \%(14)\end{array}$ & $* .001$ \\
\hline $\begin{array}{l}\text { How is your relationship with your } \\
\text { doctor? } \\
\text { - Excellent } \\
\text { - Medium } \\
\text { - Bad }\end{array}$ & $\begin{array}{l}79.70 \%(51) \\
50.00 \%(16) \\
25.00 \%(2)\end{array}$ & $\begin{array}{l}20.30 \%(13) \\
50.00(16) \\
75 \%(6)\end{array}$ & $* .001$ \\
\hline $\begin{array}{l}\text { Do you feel satisfied after each visit? } \\
\text { - Always } \\
\text { - Sometimes } \\
\text { - Never }\end{array}$ & $\begin{array}{l}81.00 \%(51) \\
50.00 \%(14) \\
30.80 \%(4)\end{array}$ & $\begin{array}{l}19.00 \%(12) \\
50.00 \%(14) \\
69.20 \%(9)\end{array}$ & $*<.001$ \\
\hline $\begin{array}{l}\text { Does your doctor educate you very well } \\
\text { about your diseases } \\
\text { - Yes } \\
\text { - No }\end{array}$ & $\begin{array}{l}74.40 \%(64) \\
27.80 \%(5)\end{array}$ & $\begin{array}{l}25.060 \%(22) \\
72.20 \%(13)\end{array}$ & $*<.001$ \\
\hline $\begin{array}{l}\text { Does your doctor answer you about all } \\
\text { your question about your health and } \\
\text { diseases? } \\
\text { - Yes } \\
\text { - No }\end{array}$ & $\begin{array}{l}72.70 \%(64) \\
31.20 \%(5)\end{array}$ & $\begin{array}{l}27.30 \%(24) \\
68.80 \%(11)\end{array}$ & $* .001$ \\
\hline
\end{tabular}

Table 5:- Association between level of compliance to doctor's advices on exercise and patient doctor relationship.

\begin{tabular}{|c|c|c|c|}
\hline & Compliance & Non-compliance & $\mathrm{P}$ value \\
\hline $\begin{array}{l}\text { Do you think your doctor is } \\
\text { versed about your health state? } \\
\text { - Yes } \\
\text { - No }\end{array}$ & $\begin{array}{l}67.10 \%(55) \\
45.50 \%(10)\end{array}$ & $\begin{array}{l}32.90 \%(27) \\
54.50 \%(12)\end{array}$ & $* .063$ \\
\hline $\begin{array}{l}\text { How is your relationship with your } \\
\text { doctor? } \\
\text { - Excellent } \\
\text { - Medium } \\
\text { - Bad }\end{array}$ & $\begin{array}{l}71.90 \%(46) \\
40.60 \%(13) \\
75.00 \%(6)\end{array}$ & $\begin{array}{l}28.10 \%(18) \\
59.40 \%(19) \\
25.00 \%(2)\end{array}$ & $* .009$ \\
\hline $\begin{array}{l}\text { Do you feel satisfied after each visit? } \\
\text { - Always } \\
\text { - Sometimes } \\
\text { - Never }\end{array}$ & $\begin{array}{l}79.40 \%(50) \\
35.70 \%(10) \\
38.50 \%(5)\end{array}$ & $\begin{array}{l}20.60 \%(13) \\
64.30 \%(18) \\
61.50 \%(8)\end{array}$ & $*<.001$ \\
\hline $\begin{array}{l}\text { Does your doctor educate you very well } \\
\text { about your diseases } \\
\text { - Yes } \\
\text { - No }\end{array}$ & $\begin{array}{l}68.60 \%(59) \\
33.30 \%(6)\end{array}$ & $\begin{array}{l}31.40 \%(27) \\
66.70 \%(12)\end{array}$ & $* .005$ \\
\hline $\begin{array}{l}\text { Does your doctor answer you about all } \\
\text { your question about your health and } \\
\text { diseases? } \\
\text { - Yes } \\
\text { - No }\end{array}$ & $\begin{array}{l}67.00 \%(59) \\
37.50 \%(6)\end{array}$ & $\begin{array}{l}33.00 \%(29) \\
62.50 \%(10)\end{array}$ & $* .025$ \\
\hline
\end{tabular}


Table 6:- Association between level of compliance to medications and characters of prescribed medications.

\begin{tabular}{|c|c|c|c|}
\hline 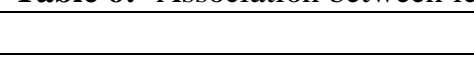 & Compliance & Non-compliance & $\mathrm{P}$ value \\
\hline $\begin{array}{l}\text { Type of medications } \\
\text { (Diabetic patients) } \\
\text { - Insulin } \\
\text { - Pills } \\
\text { - } \quad \text { Both insulin \& pills }\end{array}$ & $\begin{array}{l}48.70 \%(19) \\
84.80 \%(28) \\
33.3 \%(4)\end{array}$ & $\begin{array}{l}51.30 \%(20) \\
15.20 \%(5) \\
66.70 \%(8)\end{array}$ & $* 0.001$ \\
\hline $\begin{array}{c}\text { Numbers of medications } \\
\text { - One } \\
\text { - Two } \\
\text { - Three } \\
\text { - Four } \\
\text { - Sive } \\
\end{array}$ & $\begin{array}{l}52.40 \%(22) \\
48.40 \%(15) \\
62.50 \%(10) \\
58.30 \%(7) \\
100 \%(2) \\
0 \%(0)\end{array}$ & $\begin{array}{l}47.60 \%(20) \\
51.60 \%(16) \\
37.50 \%(6) \\
41.70 \%(5) \\
0 \%(0) \\
100 \%(1)\end{array}$ & 0.41 \\
\hline $\begin{array}{l}\text { Frequency of taking medications } \\
\text { - Once } \\
\text { - Twice } \\
\text { - Three times } \\
\text { - Four times }\end{array}$ & $\begin{array}{l}47.40 \%(9) \\
52.80 \%(28) \\
59.30 \%(16) \\
60.0 \%(3)\end{array}$ & $\begin{array}{l}52.60 \%(10) \\
47.20 \%(25) \\
40.70 \%(11) \\
40.00 \%(2)\end{array}$ & .864 \\
\hline
\end{tabular}

\section{Discussion:-}

There is strong evidence that many patients with chronic disease including diabetes mellitus and hypertension have difficulty in compliance to their recommended regimens. This results in suboptimal management and control of the disease. Poor compliance is the primary reason for suboptimal clinical benefit. It causes medical and psychosocial complications of disease, reduces patients' quality of life, and wastes health care resources (1).

For that we focused in this problem and we study the compliance with regular follow up, medications and doctor's advices on diet and exercise.

Compliance with regular follow up was very higher in our study than the earlier findings in Al Hasa district of Saudi Arabia (17) that included diabetic patients. Our results showed that $41.3 \%$ of participants had not missed any appointment in the last one year, while 5.8\% had missed an appointment once, 31.7\% twice and $21.2 \%$ more than twice. However, in $\mathrm{Al}$ Has ait was found to be $7.9 \%$ had not missed an appointment in the last one year, while 49.4\% had missed an appointment once or twice, and $41 \%$ more than twice. In other study conducted in primary health center in Saudi Arabia the non-compliance to regular follow up was $25 \%$ which is lower than our finding $(52.9 \%)$.

The non-compliance with medication in our study was $46.15 \%$ of participants which was higher than the results of study conducted in Uganda (18)28.9\%. However, our finding was lower than earlier findings in Palestine (19), Hong Kong (20), Mexico (21),Al Hasa district(17)and India(22)where it was found to be 57.9\%, 59\%, 61\%, 57.5\% and $76.3 \%$ respectively.

Regarding doctor's advices on diet $66.3 \%$ of participants in our study was complying which is approximately similar to Al Hasa study (64.66\%), lower than results of study conducted in Alexandria (23), Egypt, which was 94.3\% and higher than that in PHC in Saudi Arabia which was 40\%. However, in Alexandria study compliance was divided into two categories (92.1\% sometimes compliance with diet and $2.2 \%$ always compliance). Compliance to doctor's advice on exercise in our results was $62.5 \%$ while in Alexandria only $2.8 \%$, in Al Hasa $45.33 \%$ and in other study held at India was $37.03 \%$. (24)

There was a statistically significant difference in the compliance to regular follow up and medications regarding residency among the diabetic and hypertensive participants in our study. The compliance to regular follow up in the urban population was significantly higher than the rural population $(51,60 \mathrm{vs} 15,40)$. And also the compliance to medications in the urban population was significantly higher than rural population (58.20\% vs $23.10 \%)$. In contrast, study done in the Al Hasa have shown that rural participants have better compliance than urban participants (39.85 vs 28.96). We suggest that the lower level of compliance among rural people related to low socio-economic status and educational level and difficulty in access to health services. 
There was a statistically significant difference in compliance to doctor's advices on diet regarding to age in our study. Patients above 41 years old have highest percentage in compliance to doctor's advice on diet $(78.80 \%)$. In contrast, studies done in Abha have shown that young patients less than 40 years old have highest percentage in compliance to doctor's advice on diet.(25)

Our study shows higher rates of non- compliance to medication among patients who managed by both insulin and pills $(66.70 \%)$ followed by those managed by insulin only $(51.30 \%)$ and the least rate of non-compliance to medication among patients who managed by pills $(15.20 \%)$.

The high non-compliance rate among patient taking insulin agrees with other studies that conducted in AL-Hasa district and Scotland which found to be $20.96 \%$, 29\% respectively. That maybe because taking pills is much easier and comfortable than insulin injections or multiple medications.

There was statistically significant difference between the participants in the level of compliance to medication regarding to the presence of the disease in our study. The patients who have both diabetes and hypertension have a higher percentage in compliance to medications $(64.70 \%)$. The results of current study agree with a study conducted in USA in 2008 that reported the presence of comorbidities were associated with higher compliance to medications.

Patient doctor relationship found to be significantly associated with good compliance to regular follow up and doctor's advices on diet and exercise. Participants said that the doctor versed about their health state, give them enough information about it, have excellent relationship with their doctor and feel satisfied after each visit show better compliance. This is agreed with Alexandria study regarding to diet only. While other categories of compliance showed no statically significant difference. Also, that study conduct in Al Hasa district considers patient doctor relationship as an important factor affects the compliance.

Our study showing that patients not compliance to regular follow up and medication more likely to be poorly controlled (HA1c more than 7\%). This is proved by a study published in 2014 at AlQasim, Saudi Arabia (26) as there was statically significant difference in compliance to regular follow up and medication regarding to glycemic control.

\section{Conclusion:-}

The compliance was good among almost half of the participants. The most affecting factors was related to the presence of co-morbidities and type of prescribed medications. In addition, there was significant association between compliance and patient-doctor relationship. So, more effort should be provided to enhance the patientdoctor relationship to improve level of compliance among chronic patients.

\section{Acknowledgment:-}

We would like to express our gratitude and appreciation to all those who gave us the possibility to complete this study. We are very grateful to Taibah Medical Club for arrangement of this campaign and providing us with the kits of HbA1c and sphygmomanometer. We also would like to acknowledge with much appreciation all TMC members for their crucial role in helping us in the collection of data. In addition, we are very grateful to the supervisor of our research Dr. Suliman Amer for his great efforts and encouragement.

\section{Competing interests:-}

Authors have declared that no competing interests exist.

\section{References:-}

1. 1-World Health Organization. Adherence to long term therapies, evidence for action. Noncomunicable Diseases and Mental Health Adherence to long-term therapies project, WHO report. Geneva, Switzerland:World Health Organization, 2003; 3-5.

2. 2-Viswanathan Mohan,Yackoob K. Seedat,and RajendraPradeepa.The Rising Burden of Diabetes and Hypertension in Southeast Asian and African Regions: Need for Effective Strategies for Prevention and Control in Primary Health Care Settings. International Journal of Hypertension Volume 2013 (2013), Article ID 409083, 14 pages. 
3. National High Blood Pressure Education Program Coordinating Committee. The seventh report of the Joint National Committee on Prevention, Detection, Evaluation, and Treatment of High Blood Pressure: the JNC 7 report. JAMA. 2003; 289:2560-2571.

4. Page C, Curtis M, Sutter M, Walker M, Hoffman B. As drogas e o sistema cardiovascular. In: Page C, Curtis M, Hoffman B, autores. Farmacologia integrada. 2. ed. Barueri (SP): Manole; 2004. p. 395-413.

5. Crystal Wiley Cené, Lisa A. Cooper. Death Toll From Uncontrolled Blood Pressure in Ethnic Populations: Universal Access and Quality Improvement May Not Be Enough. Ann Fam Med. 2008 November; 6(6): 486489.

6. M. Al-Nozha, M. Abdullah, M. R. Arafah et al. Hypertension in Saudi Arabia. Saudi Medical Journal 2007; 28: 77-84.

7. P. M. Kearney, M. Whelton, K. Reynolds, P. Muntner, P. K. Whelton, J. He. Global burden of hypertension: analysis of worldwide data. The Lancet 2005; 365:217-223.

8. World health organization: Definition, diagnosis and classification of diabetes mellitus and its complications. Geneva: World health organization; 1999.

9. American Diabetes Association: Implications of the United Kingdom Prospective Diabetes Study.Diabetes Care 2004, 27(Suppl 1):28-32.

10. Zucchi P, Ferrari P, Spina ML: Diabetic foot: from diagnosis to therapy. G Ital Nefrol 2005, 22(Suppl 31):S20S22.

11. Internationa Diabetes Federation.Global diabetes scorecard. Beatriz Yáñez Jiménez, Sheree Dodd, Courtney Scott, Olivier Jacqmain.Internationa Diabetes Federation,2014;70.

12. Dunbar-Jacob J, Mortimer-Stephens MK. Treatment adherence in chronic disease. J Clin Epidemiol.2001;54:S57-60.

13. Jing J, Sklar GE, Min Sen Oh V, Chuen LiS. Factors affecting therapeutic compliance: A review from the patient's perspective. Ther Clin Risk Manag. 2008;4:269-86.

14. Zieger A. Does Better Packaging Equal Better Patient Compliance? [Online] [Last cited on 2010 Nov 20] [Last accessed on 2011 Aug 01]. Available at : http:// www.pharmamanufacturing.com/articles/2005/312.html .

15. Leslie R Martin, Summer L Williams,Kelly B Haskard,and M Robin DiMatteo. The challenge of patient adherence. Ther Clin Risk Manag. 2005;1(3):189-199[PMC].

16. Vlasnik J, Aliotta S and DeLor B. Medication adherence:factors influencing compliance with prescribedmedication plans. Case Manager, 2005;

17. Ataur R. Khan, Zaki N. Al-Abdul Lateef, Mohammad A. Al Aithan,Montaser A. Bu-Khamseen,Ibrahim Al Ibrahim,and Shabbir A. Khan. Factors contributing to non-compliance among diabetics attending primary health centers in the Al Hasa district of Saudi Arabia. J Family Community Med. 2012;19(1): 26-32.

18. Kalyango JN, Owino E, Nambuya AP. Non-adherence to diabetes treatment at Mulago Hospital in Uganda: Prevalence and associated factors. Afr Health Sci. 2008;8:67-73.

19. Sweileh W, Aker O, Hamooz S. Rate of Compliance among Patients with Diabetes Mellitus and Hypertension. An-Najah Univ J Res. 2005;19:1-12.

20. Glycemic control and medication compliance in diabetic patients in a pharmacist-managed clinic in Hong Kong.Lee VW, Leung PYAm J Health Syst Pharm. 2003 Dec 15; 60(24):2593-6.

21. Hernández-Ronquillo L, Téllez-Zenteno JF, Garduño-Espinosa J, González-Acevez E. Factors associated with therapy noncompliance in type-2 diabetes patients.Salud Publica Mex. 2003;45:191-7.

22. Shobhana R, Begum R, Snehalatha C, Vijay V, Ramachandran A. Patients' adherence to diabetes treatment. J Assoc Physicians India.1999;47:1173-5.

23. Ibrahim NK, Attia SG, Sallam SA, Fetohy EM, El-Sewi F. Physicians' therapeutic practice and compliance of diabetic patients attending rural primary health care units in Alexandria. J Fam Community Med.2010;17:1218.

24. IswaryaSanthanakrishnan, SubithaLakshminarayanan, and SitanshuSekharKar. Factors affecting compliance to management of diabetes in Urban Health Center of a tertiary care teaching hospital of south India.J Nat Sci Biol Med. 2014; 5(2): 365-368.

25. Mohammad Abdul Salam and Aesha Farheen Siddiqui. Socio-demographic Determinants of Compliance among Type 2 Diabetic Patients in Abha, Saudi Arabia. J Clin Diagn Res. 2013; 7(12): 2810-2813.

26. Dr. Ahmad Ali S. Al-Rasheedi. The Role of Educational Level in Glycemic Control among Patients with Type II Diabetes Mellitus. Int J Health Sci (Qassim). 2014; 8(2): 177-187. 